\title{
Sub Microsecond Analysis of Negative Cloud-to-Ground Lightning Flashes
}

\author{
A.I.A.Rahman ${ }^{1}$, M.A.Bahari ${ }^{2}$, Z.A.Baharudin ${ }^{3}$, A.A. Zulkefle ${ }^{4}$, M. Zainon ${ }^{5}$, \\ M.A.M. Hanafiah ${ }^{6}$ \\ 1,3,5,6 Faculty of Engineering Technology, Kampus Teknologi, Universiti Teknikal Malaysia Melaka, Malaysia \\ ${ }^{2,4}$ Faculty of Electrical Engineering, Universiti Teknikal Malaysia Melaka, Malaysia
}

\section{Article Info}

Article history:

Received Feb 1, 2018

Revised Apr 21, 2018

Accepted Apr 27, 2018

Keywords:

First return stroke

MATLAB

Negative CG

Modelling technique

\begin{abstract}
This paper expounds a software development for the identification of lightning discharged in cloud-to-ground flashes. The study was to reduce a misleading detection of the electric field radiation of lightning discharged profile by considering the important parameters of sub microseconds structure of lightning`s first return stroke. The software built in MATLAB. The software development considered the important parameters of the first return strokes such as peak value, zero crossing, rising time and fast transition time. This study used a modelling technique for training and patterning 19 return strokes from electric radiation field generated by the negative cloud-ground lightning flashes recorded in Universiti Teknikal Malaysia Melaka.19 return strokes data were recorded by using Lecoy HDO4024 with $5 \mathrm{MS} / \mathrm{s}$. The results showed the software recognized the lightning parameters such as peak value, zero crossing, rising time and fast transition time. In conclusion, the software had the potential to decreases the misleading detection of the electric field radiation generated by negative cloud-to-ground lightning flashes.
\end{abstract}

Copyright (C) 2018 Institute of Advanced Engineering and Science. All rights reserved.

\section{Corresponding Author:}

A.I.A.Rahman,

Faculty of Engineering Technology,

Kampus Teknologi, Universiti Teknikal Malaysia Melaka, Malaysia

Email: idil@utem.edu.my

\section{INTRODUCTION}

Lightning flash or strike is an immense electricity energy existed when there is different potential energy between the positively charged ions and negatively charged ions. There are basically three types of lightning flashes such as Cloud-to-Ground flashes, Cloud-to-Cloud flashes and Intro-Cloud flashes. The study focused only on the Cloud-to-Ground flash (CG). CG is a spark of electrical energy from the cloud to the ground with the tremendous amount of energy sufficient enough to bring a catastrophe towards the environment. Lightning strikes may burn anything in its path.

The lightning strikes are very dangerous and harmful towards living or non-living things. There were many cases reported by the investigators [1]-[6] where many power transmission towers, high building and human affected by the harmful lightning strikes. The characteristic of lightning flashes for each type is unique and different. The occurrence of the lighting depends on the geographical region and the clouds formations in the area.

Therefore, many researchers conducted enormous research about the Cloud-to-Ground flashes to investigate the lightning phenomenon. Previous researchers, [7]-[16] investigated the characteristics of the lightning flashes. The characterizations of the lightning flash are important to determine the mechanism of lightning flashes and their important parameters. Power engineers require the information about the parameters of a lightning strike to design specific tools for engineering testing and manufacturing. 
Baharuddin [16] stated the characterization of electric fields generated by lightning flashes by using single-station measurements could be used as ground truth because the potential effect from a thunderstorm to thunderstorm variation was smaller than the effect of using other techniques. Furthermore, the technique considered an important tool for electrical engineers and researchers because a lot of improvement towards the investigator to comprehend the potential effect of deleterious coupling of lightning fields with various objects, especially for a sensitive electronic device.

VHF interferometry and LF TOA and/or MDF had been widely used for Lightning Detection System. According to the research reported by Drue et al. (2007) he summarized the observation by Stith et al. (1999), Lang et al., (2000), and Defer et al., (2001) and he found that the VHF interferometry performed two to five times higher flash rate, however the system suffered from the blind spot if less than three receivers were used [17]. Both of ability of VHF interferometry to track single flashes. As well as to monitor the development of entire storms, the methods for detection was quite different, the systems assumed to mass a certain fraction of all lightning activity occurred in the nature caused a true number of lightning flashes remained unknown. Relative performance of each system was assessed by mutually assuming the measurements of each other as truth. Therefore, the classification naturally had to rely on criteria depending on the working principle of each system.

In Malaysia, it was believed that the Malaysian Meteorological Service (MMS) or Tenaga Nasional Berhad (TNB) used the well-known type of lightning measurement for Lightning Locating systems (LLS) such as magnetic direction finding (MDF), time of arrival (TOA) and interferometry [18]. Hartono [19] reported about the availability of data recorded by MMS or TNB. However, he stated that the data collected either by MMS or TNB consisted site error in their mapping system. He proposed the error occurred due to unresolved site errors from the existing Lightning Detection System (LDS). Besides that, Pinto and coworkers [20] also claimed the same issue as pointed out by Hartono regarding the availability data of LDS in Malaysia were not reliable. In 2009, the investigation of lightning activities ([21-23]) in Malaysia were conducted successfully. Later, the comparative study reported by P.N.S. Abd Rahman et al. [18], the data between Baharuddin et al and N. Azlinda et al [21-23] and the data recorded by TNB unmatched even when the time recording of both the data was synchronized according to Universal Time Clock (UTC). The study found by [18] stated the number of strokes count and the type of flashes were not identical.

Through our preliminary studies, many errors occurred to measure and identify the lightning flashes were reported. This study suggested that a lightning detection system must consider the important parameters for determining lightning types as well as the mechanisms. It means that a certain type of LDS should not consider only the polarity and the amplitude for detecting lightning events. There were many parameters should consider while developing LDS other than amplitude and polarity such as zero-crossing and the rising time duration of the first return stroke.

Thus, the main problem is the deficiency to develop the identification system to identify the characteristics of the lightning flashes such as the peak amplitude values, the rising time values, the zero crossing values and the fast transition of the first return stroke of the lightning events. Therefore, the objective of this study is to model a new characterization technique of Lightning Detection System (LDS) by developing a program that could provide high accuracy for detection of the lightning flash. With the aids of the technology, the lightning research will continue to develop and enhance the knowledge about the lightning phenomenon in this world.

Zero crossing is the term where the measurement of the point where the value of the rising time of the return stroke starts at zero and the falling time of the return stroke ended at zero. Zero crossing is the premier characteristic for the first return stroke because it contains other characteristics such as the peak value and rising time of the lightning strike.

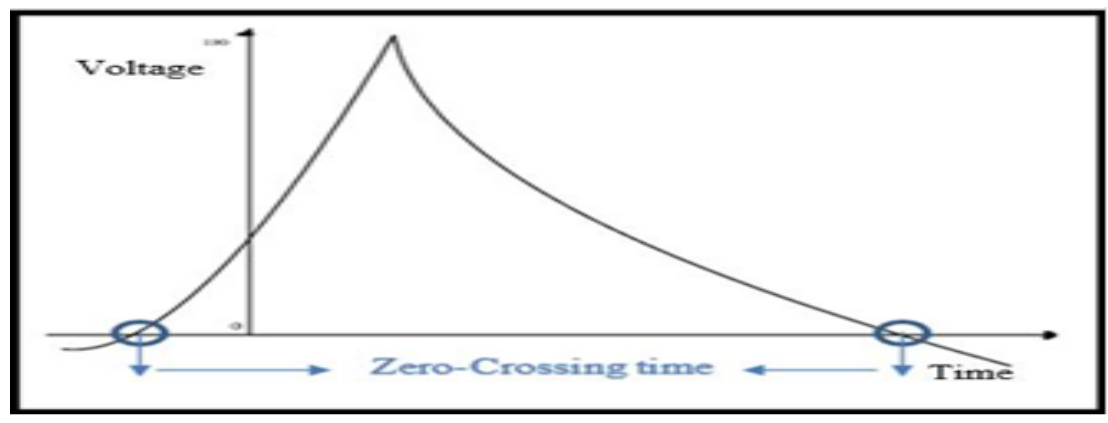

Figure1.The ideal zero-crossing time of the lightning strikes 
$10 \%$ and $90 \%$ of the rising time indicated the values of the first return stroke have reached the point where it was at $10 \%$ and $90 \%$ of the highest peak value of the first return stroke respectively. Similarly, the rising time is the duration of the first return stroke. The $10 \%$ marks the early stage of the first return stroke while the $90 \%$ marks the late stage of the first return stroke.

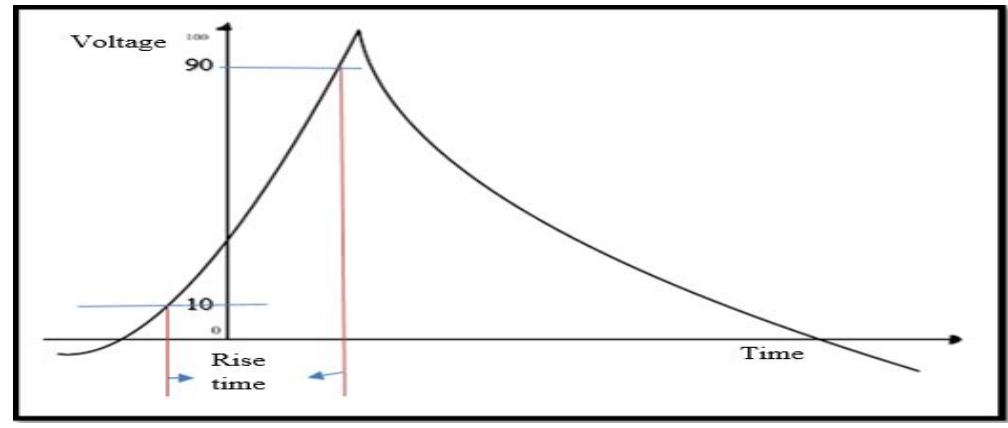

Figure 2. The ideal 10\%to $90 \%$ rising time duration of the lightning strikes

$50 \%$ marked the point where the value of the first return stroke at the half of the highest peak value of the lightning strike.

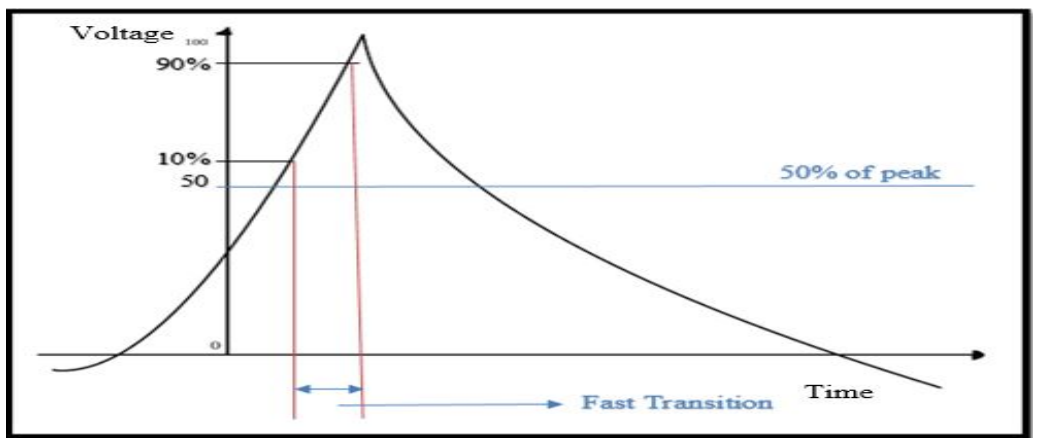

Figure $3.50 \%$ of the peak of the return stroke

\section{DATA AND METHODOLOGY}

Data were collected by using a buffer circuit, an antenna and a Leroy oscilloscope. We managed to collect 19 samples on 29-30 May 2009. The location of the station was at the Universiti Teknikal Malaysia Melaka (Industrial Campus) Ayer Keroh. MATLAB was used as a programming tool to develop the program. The program was programmed to identify the type of lightning, the peak amplitudes, the $50 \%$ of the amplitudes, the zero crossing, the slow front, fast transition and the rising time of the amplitude. The result of the research then was compared between the expected value and the tested value for the zero crossing of the first return stroke.

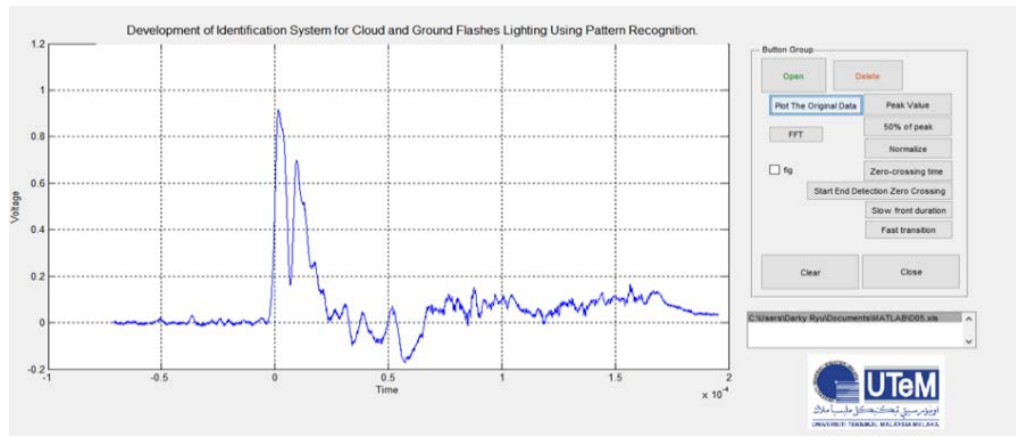

Figure 4. Graphical User Interface (GUI) of the program 
The program built with the features of the options to choose the lightning flash parameters such as peak value, $50 \%$ of the peak, normalization of the data, zero crossing value, start end detection zero crossing, slow front duration and fast transition. The result shown in the Figure 4.

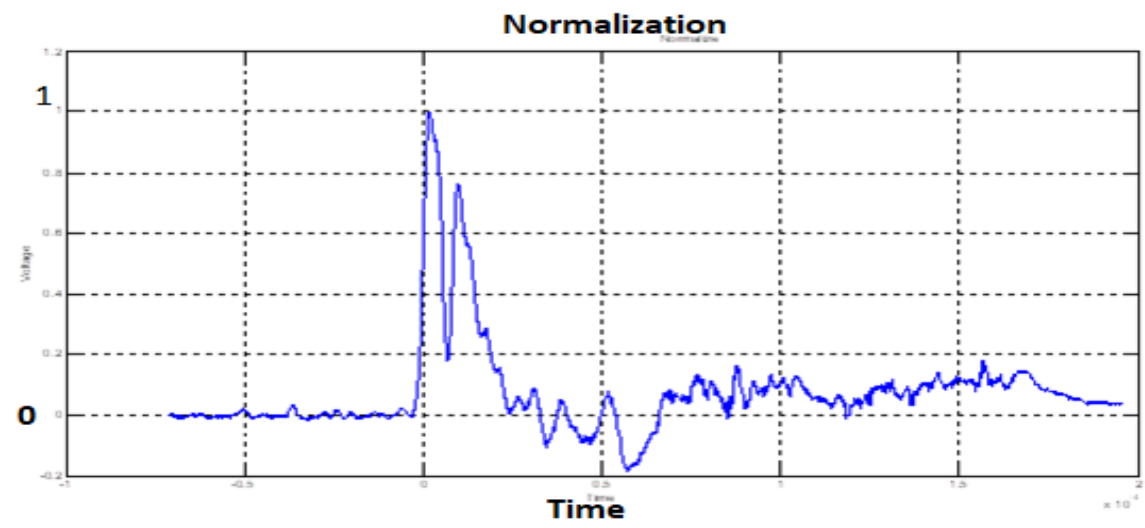

Figure 5. A graph of the data after the normalization process. The voltage value was now normalized to in term of 1

In addition, we programmed the software by normalizing all incoming data as a refinement process. We normalized all the amplitudes in term of 1.

\section{RESULTS AND ANALYSIS}

The finding of the results elaborated in this section. The software was able to identify the parameters such as the peak amplitude, 50\% peak amplitude, zero crossing, the rising time and the fast transition time.

\subsection{The Peak Amplitude}

The minimum peak value was 0.7718 (D07) while the maximum of the peak value was 4.5767 (D19). In contrast, the minimum for 50\% of the peak value was 0.3859 (D07) and the maximum for 50\% peak value was 2.2883(D19). The arithmetic means were 0.8076 and 1.6151 for $50 \%$ of peak value and peak value respectively. Besides that, the geometric means were 1.4761 and 0.7381 for $50 \%$ of peak value and peak value respectively.

Table 1. Result of Peak Value and 50\% Peak Value

\begin{tabular}{ccc}
\hline Tag & Peak Value $(\mathrm{V})$ & $50 \%$ Peak $(\mathrm{V})$ \\
\hline D01 & 0.8971 & 0.4486 \\
D02 & 1.1152 & 0.5576 \\
D03 & 1.1393 & 0.5697 \\
D04 & 1.2173 & 0.6087 \\
D05 & 0.9169 & 0.4585 \\
D06 & 1.6634 & 0.8317 \\
D07 & 0.7718 & 0.3859 \\
D08 & 1.7907 & 0.8953 \\
D09 & 1.6520 & 0.8260 \\
D10 & 1.8067 & 0.9033 \\
D11 & 1.8800 & 0.9400 \\
D12 & 1.7640 & 0.8820 \\
D13 & 1.9124 & 0.9562 \\
D14 & 1.0637 & 0.5318 \\
D15 & 1.0259 & 0.5129 \\
D16 & 1.8333 & 0.9167 \\
D17 & 1.4707 & 0.7354 \\
D18 & 2.1900 & 1.0950 \\
D19 & 4.5767 & 2.2883 \\
\hline
\end{tabular}




\subsection{Zero Crossing}

Figure 6 shows about zero crossing detection and Table 2 shows the duration of the zero crossing:

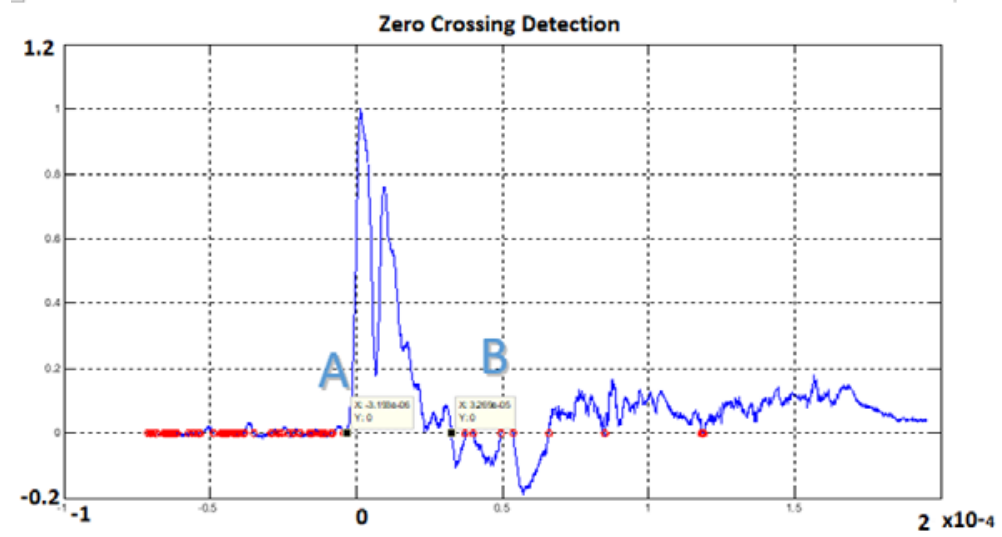

Figure 6. Starting Point indicated as A while the Ending Point indicated as B. The differences between the point $\mathrm{B}$ and the point $\mathrm{A}$ is the duration of the zero crossing in the first return stroke

Duration of Zero Crossing measured varies from $29.97 \mu$ s to $48.48 \mu$ s. The arithmetic mean of the data was 33.4us while the geometric mean of the data was $26.65 \mu$ s. Duration of zero crossing found to be in the range of 35-60 $\mu$ s. The measurement region affecred the duration of the zero crossing according to M.Hamzah et al.[24]. M.Hamzah et al. conducted the measurement in Serdang, Selangor while this data collected in this study was in Melaka. This statement justified the duration of the measured duration of the zero crossing in this study different from other research based on the location or region.

Table 2. The Duration of the Zero Crossing

\begin{tabular}{cc}
\hline Tag & $\begin{array}{c}\text { Duration of Zero Crossing } \\
(\mu \mathrm{s})\end{array}$ \\
\hline D01 & 29.97 \\
D02 & 39.06 \\
D03 & 44.76 \\
D04 & 35.28 \\
D05 & 35.88 \\
D06 & 23.90 \\
D07 & 40.43 \\
D08 & 37.78 \\
D09 & 45.82 \\
D10 & 22.44 \\
D11 & 23.53 \\
D12 & 30.68 \\
D13 & 40.10 \\
D14 & 15.77 \\
D15 & 28.32 \\
D16 & 25.17 \\
D17 & 30.15 \\
D18 & 37.16 \\
D19 & 48.48 \\
\hline
\end{tabular}

\subsection{Rising Time}

All the rising time values in Table 3 were calculated based on the $10 \%$ to $90 \%$ of the amplitude from the first return stroke. The previous researcher, F.Heidler et al (1999) stated that the maximum rising time should be in the range of 1.5 to 4us [25]. In conjunction, this study produced the rising time within the suitable range. As reported in [8] which a total of 15 data out of 19 data were in the range of maximum rising time. It was about $79 \%$ of the accuracy value of the calculated values can be accepted and reliable. 


\begin{tabular}{cc} 
Table 3. Duration of the Rising Time \\
\hline Tag & $\begin{array}{c}\text { Duration of the rising } \\
\text { time }(\mu \mathrm{s})\end{array}$ \\
\hline D01 & 2.35 \\
D02 & 2.95 \\
D03 & 5.05 \\
D04 & 2.80 \\
D05 & 2.60 \\
D06 & 4.95 \\
D07 & 6.95 \\
D08 & 3.15 \\
D09 & 1.35 \\
D10 & 1.05 \\
D11 & 3.40 \\
D12 & 2.05 \\
D13 & 4.25 \\
D14 & 2.45 \\
D15 & 2.80 \\
D16 & 1.40 \\
D17 & 1.20 \\
D18 & 2.95 \\
D19 & 5.10 \\
\hline
\end{tabular}

\subsection{Fast Transition}

The fast transition is $50 \%$ of the amplitude value taken from the first return stroke. The smallest fast transition time was $1.00 \mu$ s while the highest fast transition time was $8.50 \mu$ s according to the data in this research. In correlation with the data from Table 4, 15 out of 19 rising time values were acceptable.

Table 4. Duration of the fast transition time

\begin{tabular}{cc}
\hline Tag & $\begin{array}{c}\text { Duration of the fast } \\
\text { transition time }(\mu \mathrm{s})\end{array}$ \\
\hline D01 & 2.35 \\
D02 & 2.95 \\
D03 & 5.05 \\
D04 & 2.80 \\
D05 & 2.60 \\
D06 & 4.95 \\
D07 & 6.95 \\
D08 & 3.15 \\
D09 & 1.35 \\
D10 & 1.05 \\
D11 & 3.40 \\
D12 & 2.05 \\
D13 & 4.25 \\
D14 & 2.45 \\
D15 & 2.80 \\
D16 & 1.40 \\
D17 & 1.20 \\
D18 & 2.95 \\
D19 & 5.10 \\
\hline
\end{tabular}

\section{CONCLUSION}

The software was created. This research was about the development of identification system for negative cloud-to-ground lightning flashes using pattern recognition. This software was to identify and extract the lightning parameters such as peak value, zero crossing value, rising time and fast transition time. The software detected all the parameters of the lightning and produced results which are parallel with the objectives of this research. Despite that, there was a limitation in this research where there were not many data were investigated because the location`s availability to measure the data was limited. the recommendation for this research to increase the accuracy of the software by adding more features such as classification of lightning flashes. Furthermore, to improve the reliability and accuracy of the software ones need to increase the samples for future research. 


\section{REFERENCES}

[1] J. Eriksson. The incidence of lightning strikes to power lines. IEEE Trans. Power Deliv. 1987; 2(3): 859-870.

[2] Farouk A.M. Rizk. Transactions on Power. Model. Transm. Line Expo. To Direct Lightning Strokes.1991; 5(1):23-29.

[3] A. Nucci, F. Rachidi, M. V. Michel, and C. Mazzetti. Lightning-Induced Voltages on Overhead Lines. IEEE Trans. Electromagn. Compat: 1993; 35(1): 75-86.

[4] F. Rachidi, C. A. Nucci, M. Ianoz, and C. Mazzetti. Influence of a lossy ground on lightning-induced voltages on overhead lines. IEEE Trans. Electromagn. Compat. 1996; 38(3):250-264.

[5] D.Power, S.Bureau, P.Grid.”Lightning Performance and Its Prevention for Quadruple-circuit Transmission Line with 220kV/110kV Voltage in a Tower,” TELKOMNIKA Indones. J. Electr. Eng. 2013; 11(10): 5833-5841.

[6] H.Zeng, L.Lin, Z.Wang et al.”Study on Lightning Intruding Overvoltages in Yantan Extension Substation.TELKOMNIKA Indones. J. Electr. Eng. 2014 ;12(4): 2458-2464.

[7] Nag and V. A. Rakov. Some inferences on the role of lower positive charge region in facilitating different types of lightning. Geophys. Res. Lett. 2009a; 36: L05815: doi:10.1029/2008GL036783.

[8] S.B.Smith. A Comparison of Satellite-Observed Cloud-Top Cooling and the Onset of Cloud-to-Ground Lightning. 18th Conference on Severe Local Storms. 1996; 479-482.

[9] J. Montanya, D. Aranguren, N. Pineda, G. Sola, D. Romero and V. March. Total lightning, electrostatic field and meteorological radar applied to lightning hazard warning. 20th International Lightning Detection Conference (ILDC). Proceedings. Tucson, CD-ROM, 2008.

[10] J. Wu,Y. F. Chen and Z.C. Zeng "Method of Making a Current Pre- thundering Report was to Use the Files of the Ground Electric Field Instrument and Locating the Lightning,” Meteorological And Environmental Sciences. 2009;32(1): 47-50.

[11] Z.A. Baharudin, M. Fernando, N.A. Ahmad, J.S. Makela, M. Rahman, V. Cooray. Electric field changes generated by the preliminary breakdown for the negative c1oud-to-ground lightning flashes in Malaysia and Sweden. J. Atmos. Solar-Terr. Phys. 2012a; 84-85: 15-24.

[12] Z.A. Baharudin, N.A. Ahmad, M. Fernando, V. Cooray, J.S. Makela. Comparative study on preliminary breakdown pulse trains observed in Johor, Malaysia, and Florida, USA. Atmos. Res. 2012b; 117: 111-121.

[13] Wu, Y. Takayanagi, I. Funaki, S. Yoshida, To. Ushio, Z-l. Kawasaki, I. Morimoto, M. Shimizu. Preliminary breakdown pulses of cloud-to-ground lightning in winter thunderstorms in Japan," J. Atmos. Solar Terr. Phys. 2013;102: 91-98.

[14] Marshall, W. Schulz, N. Karunarathna, S. Karunarathne, M. Stolzenburg, C. Vergeiner, I. Warner. On the percentage of lightning flashes that begin with initial breakdown pulses. J. Geophys. Res., 2014; 119: doi:10.1002/2013JD020854.

[15] C.H. Wooi, Z. A. Malek, N. A. Ahmad, M. Mokhtari, B. Salimi. Statistical Analyswas on Preliminary Breakdown Pulses of Positive Cloud-to-Ground Lightning in Malaysia. International Journal of Electrical and Computer Engineering (IJECE).2016; 6(2): 844-850.

[16] Z.A. Baharudin, Characterization of ground flashes from tropic to northern region. PhD Thesis. Uppsala Universitas: Sweden: 2014

[17] Drue, T. Hauf, U. Finke, S. Keyn, and O. Kreyer. Comparison of a SAFIR lightning detection network in northern Germany to the operational BLIDS network. J. Geophys. Res. Atmos. 2007; 112(18): 1-10.

[18] P. N. S. Ab Rahman, Z. Abadi Baharudin, and N. H. Abdul Rahim. Misdentification of Type of Lightning Flashes in Malaysia. TELKOMNIKA Indones. J. Electr. Eng.2014; 12(8):5938-5975.

[19] Abidin HZ, Ibrahim R. Thunderstorm day and ground flashe density in Malaysia. The conference of National Power and Energy. 2003.

[20] Pinto O Jr, Pinto IRCA, Naccarato KP. Maximum cloud-to-ground lightning flash densities observed by lightning location systems in the tropical region: A review. Journal of Atmospheric Research. 2006; 84: 189-200.

[21] Baharudin ZA, N Azlinda, Fernando M, Cooray V, Mäkelä JS, M Rahman. Electric field changes generated by the preliminary breakdown for the negative cloud-to-ground lightning flashes in Malaysia and Sweden. Journal of Atmospheric Solar Terrestrial Physics. 2012; 84-85: 16-24.

[22] Baharudin ZA, N Azlinda, Fernando M, Cooray V, Mäkelä JS. Comparatative study on preliminary breakdown pulse trains observed in Johor, Malaysia and Florida, USA. Journal of Atmospheric Research. 2012; 117: 111-121.

[23] N Azlinda, M Fernando, Baharudin ZA, V Cooray, Ahmad H, Abdul Malek Z. The characteristics of Narrow Bipolar Pulses in Malaysia. Journal of Atmospheric and Solar Terrestrial Physics. 2010; 72: 534-540.

[24] M.Hamzah, M.Ab Kadir, C. Gomes et al. Unusually long duration lightning electric field return strokes in Malaysia. International Conference on Lightning Protection. 2014;1691-1694.

[25] F.Heidler, J.M.Cvetic, B.V.Stanic. Calculation of Lightning Current Parameter. IEEE Transaction on Power Delivery, 1999;14(2). 